\title{
The scourge of head injury among commercial motorcycle riders in Kampala; a preventable clinical and public health menace
}

\author{
Louis H Kamulegeya ${ }^{1}$, Mark Kizito ${ }^{1}$, Rosemary Nassali ${ }^{2}$, Shiela Bagayana ${ }^{3}$, Alex E Elobu ${ }^{1}$
}

1. Department of Surgery, Makerere University College of Health Sciences

2. Department of Nursing, Makerere University College of Health Sciences

3. Departement of Biomedical Engineering, Makerere University College of Health Sciences

\begin{abstract}
Background: Trauma is an increasingly important cause of disease globally. Half of this trauma is from road traffic injuries with motorcycles contributing $21-58 \%$. Low protective gear use, lack of regulation and weak traffic law enforcement contribute to unsafe nature of commercial motorcycles also known as "boda boda" in Uganda.

Objectives: To determine the prevalence of protective gear use, the occurrence of head injury and the relationship between the two among commercial motorcycle riders in Kampala.

Methods: Following ethical approval we recruited consecutive consenting participants to this analytical cross-sectional study. Data was collected using pretested interviewer administered questionnaires, double entered in Epidata and analyzed with STATA. Proportions and means were used to summarize data. Odds ratios were calculated for association between wearing helmets and occurrence and severity of head injury.

Results: All 328 participants recruited were male. Of these, 18.6\% used Protective gear and $71.1 \%$ sustained head injury. Helmets protected users from head injury (OR $0.43,95 \%$ CI, $0.23-0.8$ ) and significantly reduced its severity when it occurred. Conclusion: Protective gear use was low, with high occurrence of head injury among commercial motorcycle riders in Uganda. More effective strategies are needed to promote protective gear use among Uganda's commercial motorcycle riders.
\end{abstract}

Keywords: Boda-boda, okada, commercial motorcycle, head injury, protective gear, helmet, Mulago hospital.

DOI: http://dx.doi.org/10.4314/ahs.v15i3.41

Cite as: Kamulegeya LH, Kizito M, Nassali R, Bagayana S, Elobu AE. The scourge of head injury among commercial motorcycle riders in Kampala; a preventable clinical and public health menace. Afri Health Sci. 2015;15(3):1016-22. doi: http://dx.doi.org/10.4314/abs. $v 15 i 3.41$

\section{Introduction}

Road traffic injuries are the leading cause of injury-related deaths and disability worldwide but more so in low and middle income countries ${ }^{1-3}$. Injuries are increasingly becoming an important contributor to disability adjusted life years worldwide ${ }^{2,4}$

Trauma is the fifth or sixth leading cause of disease burden in Uganda ${ }^{5}$ with road traffic crashes topping the causes of injury in Uganda at $48 \%$.

In East Africa, motorcycle related crashes contribute

\author{
Corresponding author: \\ Alex E Elobu \\ Makerere University \\ College of Health Sciences, \\ Department of Surgery, \\ P.O.BOX 7072, Kampala, \\ Fax: +256-414532591, \\ Tel: +256-782714892, \\ Email: elobuemmy@yahoo.co.uk
}

$21-58.8 \%$ of the road traffic crashes with head injury being common ${ }^{7-10}$. Most of the crash victims require surgical intervention and survivors tend to have chronic disabilities ${ }^{8}$.

The commercial motorcycles, also known as "Boda-boda" in East Africa or "Okada" in West Africa as previously described are popular in both urban and rural setting as a quick means of transport ${ }^{8-10}$. With over 100,000 commercial motorcycles in Kampala alone ${ }^{8}$, this lucrative industry generates more than US $\$ 400,000$ daily. Attempts by institutions e.g. the Uganda Police Force, Kampala Capital City Authority to regulate the industry have been received with mixed feelings, resistance by operators, political interference and have not yet been successful ${ }^{8,11}$. Observed crash helmet use us is low at $30.5 \%$ and $1 \%$ among riders and passengers respectively ${ }^{12}$. Efforts to promote road safety especially protective gear use have been curtailed by underfunding, weak implementation and erratic traffic law enforcement. The Uganda Police Force which is constitutionally mandated to enforce such law reports lack of human and non-human resources and inadequate police training to meet current and future challenges of traffic policing. ${ }^{7-8,10,13}$. 
Despite the burden of the problem in Uganda, motorcycle injuries have not received the attention they deserve. There is need for more literature on these injuries that will inform stakeholders on the magnitude of the problem $^{14}$. Since the majority of motorcycle injuries are preventable, a clearer understanding of the magnitude, contributing factors and injury patterns is essential for establishment of prevention strategies as well as treatment protocols ${ }^{7,14}$.

This study documents the prevalence of head injury and use of protective gear among motorcycle accident victims seen at Mulago hospital and makes a case for the use of protective gear to prevent motorcycle related injuries or mitigate their severity.

\section{Methods}

Following ethical approval from Mulago hospital Institutional Review Board an analytical cross sectional study was conducted in 2013 at the Accidents and Emergency Department of Mulago Hospital. Mulago hospital is a 1,500 bed national referral hospital and the teaching hospital for Makerere University. On average, 10 to 20 motorcycle crush victims are attended to daily. About $65 \%$ of Mulago Hospital trauma victims come from Kampala city and surrounding areas ${ }^{14}$.
Consecutive consenting participants were prospectively enrolled. Participants for whom it was impossible to determine if they were wearing protective gear at the time of the crush were excluded. The researchers participated in the initial evaluation and resuscitation of the patients. Participant biodata, injury history and neurological examination findings were collected using pretested interviewer administered questionnaires, entered into Epidata Entry and analyzed with STATA 12. Head injury severity was measured using the Glasgow Comma Scale. Data were tabulated. Proportions and means were used to summarize the data. Chi square and Bartlett's tests were used to compare the head injury and no head injury groups. Odds ratio was calculated for the relationship between protective gear use and occurrence and severity of head injury.

\section{Results}

Of the 338 participants recruited, questionnaires were completed for $328(97 \%)$. Ten participants were excluded because it was impossible to determine if they were wearing any protective gear at the time of injury.

Table 1: Socio-demographic characteristics of the study population

\begin{tabular}{|c|c|c|c|c|c|}
\hline Characteristic & $\begin{array}{ll}\text { Head Injury } \\
\text { present }\end{array}$ & No head Injury & $\begin{array}{l}\text { Total }(328) \\
\text { n }(\%)\end{array}$ & $\begin{array}{l}\text { Test } \\
\text { statistic }\end{array}$ & $\begin{array}{l}\text { p- } \\
\text { value }\end{array}$ \\
\hline \multicolumn{6}{|l|}{$\overline{\text { Sex }}$} \\
\hline Male & $233 \quad(71)$ & $95(29)$ & $328(100 \%)$ & & \\
\hline Age in years (Mean, & $30.29(9.6)$ & $28.28(8.9)$ & $29.01(9.15)$ & $0.963^{*}$ & 0.326 \\
\hline $\mathrm{SD}[95 \% \mathrm{CI}])$ & $28.32-37.27$ & $27.33-29.63$ & $28.01-30$ & & \\
\hline \multicolumn{6}{|l|}{ Ethnicity } \\
\hline Bantu & $212(71.1)$ & $86(28.9)$ & $298(90.9 \%)$ & $3.250^{\ddagger}$ & 0.355 \\
\hline Nilotics & $17(73.9)$ & $6(26.1)$ & $23(7.0 \%)$ & & \\
\hline Nilo-Hamites & $2(100)$ & $0(0)$ & $2(0.6 \%)$ & & \\
\hline Sudanese & $2(40)$ & $3(60)$ & $5(1.5 \%)$ & & \\
\hline $\begin{array}{l}\text { Level of Formal } \\
\text { Education }\end{array}$ & & & & & \\
\hline None & $39(81.3)$ & $9(18.8)$ & $48(14.6 \%)$ & $11.112^{\ddagger}$ & 0.025 \\
\hline Primary & $104(75.4)$ & $34(24.6)$ & $138(42.1 \%)$ & & \\
\hline Secondary & $72(62.1)$ & $44(37.9)$ & $116(35.4 \%)$ & & \\
\hline Vocational training & $5(100)$ & 0 & $5(1.5 \%)$ & & \\
\hline Tertiary & $13(61.9)$ & $8(38.1)$ & $21(6.4 \%)$ & & \\
\hline
\end{tabular}


The mean age was 29.01 years $(\mathrm{SD}=9.15)$, and all participants were male. The majority $(90 \%)$ were of Bantu ethnicity and slightly over half (56.7\%) had primary level or no formal education at all.

Table 2: Comparative analysis of the study arms

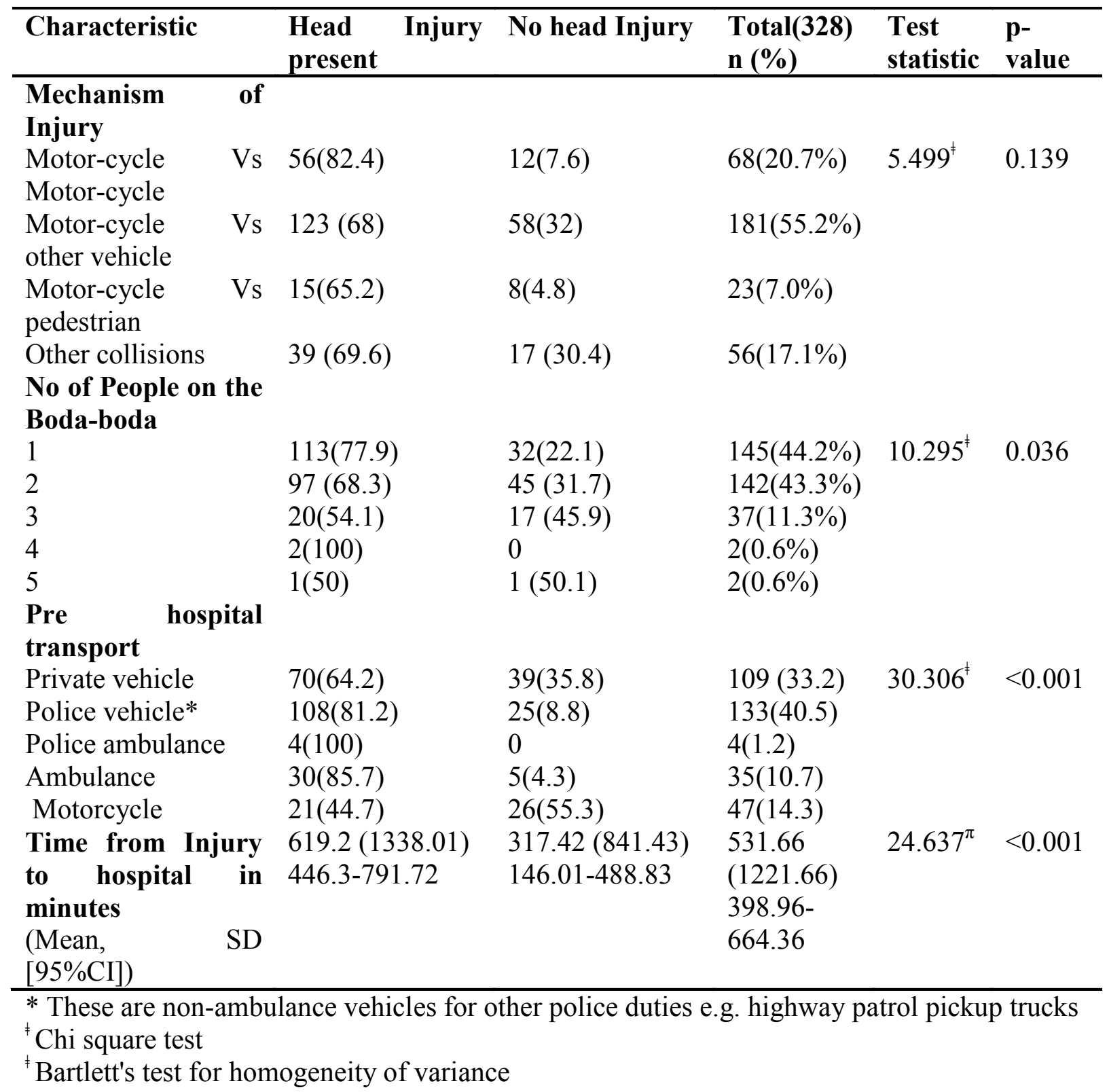

In half $(55.2 \%)$ of the times, crashes were between a motor cycle and avehicle. On most occasions (87.5\%) there were one or two people on the motorcycle. Nearly three quarters $(73.7 \%)$ of the crash victim reached hospital by means of a private car or police vehicle (not ambulance). Notably, only $11.9 \%$ were brought by ambulance. On average it took up to 531 minutes (8 hours and 55 minutes) for injured victims to reach the hospital. 
Head injury present

\begin{tabular}{llll}
\hline Protective gear & $\begin{array}{l}\text { YES } \\
\mathrm{n}(\%)\end{array}$ & $\begin{array}{l}\text { NO } \\
\mathrm{n}(\%)\end{array}$ & $\begin{array}{l}\text { TOTAL } \\
\mathrm{n}(\%)\end{array}$ \\
YES & $34(55.7 \%)$ & $27(44.3 \%)$ & $61(18.6 \%)$ \\
NO & $199(74.4 \%)$ & $68(25.5 \%)$ & $267(81.4 \%)$ \\
TOTAL & $233(71 \%)$ & $95(29 \%)$ & $328(100 \%)$ \\
\hline
\end{tabular}

Of the 328 participants recruited, only 61 (18.6\%), wore protective gear and $233(71 \%)$ sustained head injury. Wearing of protective gear was protective of the pre- venting head injury with a statistically significant odds ratio of $0.43(\mathrm{p}=95 \% \mathrm{p}$ value $=0.004$, CI $0.23-0.8)$. Conversely, not wearing head gear was associated with a 2.3 fold increase in odds of sustaining head injury.

Table 4: Relating the severity of head injury and wearing of protective gear

\begin{tabular}{lllll}
\hline \multirow{2}{*}{$\begin{array}{l}\text { Protective } \\
\text { gear }\end{array}$} & \multicolumn{5}{l}{ Severity of Head Injury } \\
\cline { 2 - 4 } & $\begin{array}{l}\text { Severe } \\
\mathrm{N}(\%)\end{array}$ & $\begin{array}{l}\text { Moderate } \\
\mathrm{N}(\%)\end{array}$ & $\begin{array}{l}\text { Mild } \\
\mathrm{N}(\%)\end{array}$ & Total \\
NO & $23(92 \%)$ & $95(92.2 \%)$ & $81(77.1 \%)$ & 199 \\
YES & $2(8 \%)$ & $8(7.77 \%)$ & $24(22.9 \%)$ & 34 \\
TOTAL & $25(10.7 \%)$ & $103(44.2 \%)$ & $105(45.1 \%)$ & 233 \\
\hline
\end{tabular}

Only $14.6 \%$ of the participants who sustained head injury reported wearing any protective gear at the time of the crash. Also, the proportion of the participants with severe head injury who were not wearing protective gear $(92 \%)$ was statistically significantly $(\mathrm{p}$ value $=$ 0.005) higher than those with mild head injury who also were not wearing protective gear $(77.1 \%)$ This shows that wearing of protective gear reduced the severity of head injury among crash victims.

\section{Discussion}

This study revealed a very low prevalence of protective gear use and an alarmingly high occurrence of head injury, findings that are of great clinical and public health importance. 
All the study participants were male, with average age of 29 years. The majority $(90.9 \%)$ was of Bantu ethnicity and over three quarters $(77 \%)$ had no formal or primary level education. This participant population generally compares to that of other studies in other low and middle income countries ${ }^{7,15-16}$.

In this study only $18.6 \%$ of the participants reported wearing crash helmets at the time of the road crash. This is somewhat higher than the 13\% reported in 2011 in the same hospital ${ }^{12}$. It compares to the other reported prevalence rates of $17.1-24 \%$ in Uganda and Tanzania ${ }^{7-8}$ but is higher than that reported in Nigeria at only $8 \%{ }^{17}$. This low prevalence arises from the observed low rate of protective gear use of $30.5 \%$ among riders in Kampala ${ }^{12}$.

Even if over estimated, the $18.1 \%$ rate of protective gear use is unacceptably low indicating that our currentefforts to promote the use of protective gear are largely inadequate and have had very limited positive impact. There was an extremely high proportion of head injury at $71 \%$ of all motorcyclists. The reported proportion of head injury was $10.1 \%$ in $2001^{9}, 35.5 \%$ in $2009^{8}$ and $71.1 \%$ in 2013 in this study. This alarming development could be explained by the persistent low use of protective gear and increased rider recklessness at a time when the commercial motorcycles being used are more powerful ${ }^{18}$ and capable of higher energy transfers leading to more severe injuries.

This study was restricted to motorcycle riders. Pedestrians may not undergo similar energy transfers as riders and may be less likely to sustain head injury. This may explain the rather high head injury proportion in this study that was limited to riders.

In this study, helmet use was protective of head injury with an Odds ratio of 0.43 (95\% CI 0.23-0.8). Conversely, not wearing protective gear increased the odds of sustaining head injury by 2.3 fold. This compares to previous studies in which the OR was from 2.5 to $4.4^{19}$ 20. Also there was a trend towards more severe forms of head injury for motorcyclists who were not wearing protective gear.

Several systematic reviews recommend helmets for preventing crash fatalities and head injury ${ }^{21-22}$. At a provincial hospital in Kenya, all trauma fatalities had head injury among other injuries15. In Tanzania, none of the crash victims who wore helmets sustained head injury. Therefore, all stakeholders should promote protective gear use among motorcyclists and their passengers.
Non-use of protective gear is a major clinical problem because the resultant head injury is associated with high mortality and morbidity, prolonged hospital stay and chronic disability among the victims ${ }^{8,21-22}$. It is also a significant public health problem partly because trauma related treatment is very costly at about US $\$ 369$ per victim of commercial motorcycle related injuries ${ }^{8}$. Motorcycle related injuries consume $4.2 \%$ of Mulago hospital annual budget ${ }^{23}$. Trauma alone takes up nearly $2 \%$ of Uganda's Gross Domestic Product ${ }^{14}$. For a country that struggles with under funding of healthcare ${ }^{24}$, these are colossal sums of money to spend on a single preventable disease condition. On the other hand, as seen in this study and many others, most victims are young men in their more productive years, ${ }^{6,8,10,15-16}$. The resultant reduced productivity and chronic disability that many of these crash victims suffer makes them a financial and social burden to their families and the community at large. With the right strategies, these injuries can be reduced or their severity mitigated significantly. This would potentially reduce the associated huge expenses and social misery. This study attests to the inadequacy of the efforts to promote helmet use in Uganda.

In slightly over half of the cases in this study as in several others ${ }^{9,15}$, the crashes were between a motorcycle and other vehicles. Could this be due to low visibility of the motorcycles to other drivers ${ }^{25}$ or the previously reported recklessness ${ }^{18}$ Rider conspicuity to other road users can be significantly improved by use of reflective clothing and "always on" head lamp policy as show from previous work ${ }^{25}$. The occurrence of head injury had no significant relationship with number of people on the motorcycle at the time of crash. Being that in most instances $(87.5 \%)$ the number of people was within the legal limit of two, there is need for additional preventive measures. Nearly two thirds of victims reached the hospital by way of private vehicle and police vehicle. Hopefully the current efforts by police to increase the emergency response capacity ${ }^{13}$ will lead to more people arriving in safer conditions by ambulance.

The Uganda Police Force recognizes that enforcing traffic laws reduces road traffic injuries but reportedly lacks the capacity to do so ${ }^{13}$. Traffic law enforcement has significantly reduced road traffic injures in Rwanda and Tanzania and needs to be supported in Uganda as well ${ }^{26-27}$.

\section{Limitations}

We may not have captured all motorcycle crush victims 
as many victims including those who sustained minor or fatal injuries may not have been seen at Mulago hospital. Also, because not wearing helmets is unsafe and illegal, motorcyclists could have claimed to have been wearing protective gear thus introducing reporting bias leading to a spuriously higher prevalence. The findings of this study should thus be interpreted with caution.

\section{Conclusion}

This study revealed that the vast majority of motorcycle crash victims seen at Mulago hospital sustained head injury. Only a minority of these victims were using protective gear at the time of the crash. Also, the use of protective gear significantly reduced the occurrence and severity of head injury among crash victims.

Therefore, more efforts need to be invested in increasing the use of protective gear to reduce the occurrence and severity of head injury among commercial motorcycle riders in Uganda.

\section{Competing interest}

The authors declare no conflict of interest.

\section{Acknowledgements}

This research project was funded by a research grant from the Global Partners of Anesthesia and Surgery (GPAS) through the department of surgery at Makerere University College of Health Sciences. The funders had no influence on the design and conduct of the study or its data analysis and manuscript writing.

\section{References}

1. Lagarde E. Road Traffic Injury Is an Escalating Burden in Africa and Deserves Proportionate Research Efforts. PLoS Med. [doi:10.1371/journal.pmed.0040170]. 2007;4(6):170.

2. Nantulya VM, Reich MR. The neglected epidemic: road traffic injuries in developing countries. BMJ. 2002 May 11;324(7346):1139-1141.

3. Peden M, Scurfield R, Sleet D, Mohan D, Hyder AA, Jarawan E, Mathers. World Report on Road TrafficInjury Prevention Geneva. World Health Organisation;. 2004.

4. Laxminarayan R, Mills AJ, Breman JG, Measham AR, Alleyne G, Claeson M, et al. Advancement of global health: key messages from the Disease Control Priorities Project. Lancet. 2006 Apr 8;367(9517):1193-1208.

5. Burden of disease study. Ministry of Health, Uganda. 1996.

6. Center-Uganda IC. Final report for the Hospital and Trauma Surveilence Program in Uganda. 2010:8.
7. Chalya P, Mabula J, Dass R, Mbelenge N, Ngayomela I, Chandika A, et al. Injury characteristics and outcome of road traffic crash victims at Bugando Medical Centre in Northwestern Tanzania. Journal of Trauma Management \& Outcomes. 2012;6(1):1 PubMed .

8. Galukande M, Jombwe J, Fualal J, Gakwaya A. Boda-boda Injuries a Health Problem and a Burden of Disease in Uganda: a Tertiary Hospital Survey. East and Central African Journal of Surgery 2009;14(2):33 PubMed -37

9. Naddumba E. A cross sectional retrospective study of boda boda injuries at Mulago Hospital in Kampala. Uganda. East Cent Afr J Surg. 2004;9:44 - 47.

10. Kitara DL. Boda Boda Injuries in Gulu Regional Hospital, Northern Uganda. East and Central African Journal of Surgery. 2011;16(2):97-101.

11. Tumwebaze F. Ministerial Statement on Motorcycle registration. [cited $201507 \mathrm{Feb}$; Available from: http://www.officeofthepresident.go.ug/index.php/ tenders/item/127-ministerial-statement-on-motorcycle-registration.

12. http://www.ipifa.net/downloads/presentations/ Boniface $\% 20$ MutatinaUganda $\% 20-\% 20$ Helmet $\% 20$ Surveys \%20abstract.pdf.accessed 31/10/13 4:50 PM.

13. Force TUP. Annual Crime and Traffic/ Road Safety Report. 2012:31.

14. Hsia RY, Ozgediz D, Mutto M, Jayaraman S, Kyamanywa P, Kobusingye OC. Epidemiology of injuries presenting to the national hospital in Kampala, Uganda: implications for research and policy. Int J Emerg Med. 2010;3(3):165 PubMed -172.

15. Khanbhai M, Lutomia MBL. Motorcycle Accident injuries seen at Kakamega Provincial Hospital in Kenya. East and Central African Journal of Surgery. 2012;17(1):4346.

16. Chalya P, Mabula J, Ngayomela I, Kanumba E, Chandika A, Giiti G, et al. Motorcycle injuries as an emerging public health problem in Mwanza City, north-western Tanzania. Tanzan J Health Res. 2010;12:214 - 221.

17. Johnson OE. Prevalence and pattern of road traffic accidents among commercial motorcyclists in a city in Southern Nigeria. Educational Research. 2012;3(6):537542.

18. Kigera J W M, Naddumba EK. Patterns Of Injuries After Road Traffic Crashes Involving Bodabodas The Annals of African Surgery. 2010;5:12-15 PubMed. 19. LaTorre G, Bertazzoni G, Zotta D, van Beeck E, Ricciardi G. Epidemiology of accidents among users of two-wheeled motor vehicles. A surveillance study in two Italian cities. Eur J Public Health. 2002 Jun;12(2):99103. 
20. Conrad P, Bradshaw YS, Lamsudin R, Kasniyah N, Costello C. Helmets, injuries and cultural definitions: motorcycle injury in urban Indonesia. Accident Analysis and Prevention 1996 Mar;28(2):193-200.

21. MacLeod JB, Digiacomo JC, Tinkoff G. An evidence-based review: helmet efficacy to reduce head injury and mortality in motorcycle crashes: EAST practice management guidelines. J Trauma. 2010 Nov;69(5):11011111.

22. Liu B, Ivers R, Norton R, Blows S, Lo SK. Helmets for preventing injury in motorcycle riders. Cochrane Database Syst Rev. 2004(2):CD004333.

23. Kigera J NL, Naddumba E K. The Impact of Bodaboda Motor Crashes on the Budget for Clinical Services at Mulago Hospital, Kampala. East and Central African Journal of Surgery. 2010;15(1):57-61.
24. Zikusooka CM, Kyomuhang R, Orem JN, Tumwine M. Is health care financing in Uganda equitable? Afr Health Sci. 2009 Oct;9 Suppl 2:S52-58.

25. Wells S, Mullin B, Norton R, Langley J, Connor J, Jackson R, et al. Motorcycle rider conspicuity and crash related injury: case-control study. BMJ. 2004 2004-0408 PubMed 00:00:00;328(7444):857.

26. Twagirayezu E, Teteli R, Bonane A, Rugwizangoga E. Road traffic injuries at Kigali University Central Teaching Hospital, Rwanda. East Cent Afr J Surg. 2008;13:73 - 76

27. Mcharo B. Motorcycle crash: injuries pattern and associated factors among patients treated at Muhimbili Orthopaedic Institute. Dissertation for Master of Medicine (Orthopaedic and Traumatology) of Muhimbili University of Health and Allied Sciences. 2012. 